\title{
Euparyphium albuferensis and Echinostoma friedi (Trematoda: Echinostomatidae): experimental cercarial transmission success in sympatric snail communities
}

\author{
Carla Muñoz-Antoli, Antoni Marin, Amparo Vidal, Rafael Toledo and José Guillermo Esteban \\ Departamento de Parasitología, Facultad de Farmacia, Universidad de Valencia, Av. Vicente Andrés Estellés s/n, \\ 46100 Burjassot - Valencia, Spain
}

Key words: Euparyphium albuferensis, Echinostoma friedi, cercarial transmission success, compatibility, sympatry, Radix peregra, Lymnaea fuscus, Physella acuta, Gyraulus chinensis

\begin{abstract}
Euparyphium albuferensis and Echinostoma friedi cercarial infectivity to four species of sympatric snails was examined under single- or multiple-choice laboratory conditions to show the level of parasite-snail host compatibility. Radix peregra, Lymnaea fuscus, Physella acuta and Gyraulus chinensis act as second intermediate hosts of both parasite species although different cercarial transmission success (CTS) was observed. In single-host experiments, $R$. peregra and $P$. acuta showed a high degree of compatibility with E. albuferensis, while only P. acuta in the case of E. friedi. In two-choice snail communities, a snail with high CTS increased the values of another with low compatibility, in both parasite species. In multiple-choice snail communities, high CTS of some hosts decreased, while low CTS of other hosts increased. The degree of parasite-host compatibility of each snail species could be determined by the presence of other snails in the community.
\end{abstract}

Euparyphium albuferensis Esteban, Toledo, Sanchez et Muñoz-Antoli, 1997 and Echinostoma friedi Toledo, Muñoz-Antoli et Esteban, 2000 (Trematoda: Echinostomatidae) are sympatric parasites of rats in the Albufera Natural Park of Valencia (Spain) (Esteban et al. 1997, Toledo et al. 2000). These two parasite species present an aquatic three-host life cycle, using Gyraulus chinensis (Dunker) (Planorbidae) and Radix peregra (Müller) (Lymnaeidae), respectively, as natural first intermediate hosts. The general low specificity towards the second intermediate host is well known in digenetic trematodes, and these two parasites are able to use these and other different snail species. In fact, echinostomatid metacercarial stages have been recorded in a variety of molluscs, planarians, fish and amphibian larvae (Huffman and Fried 1990). However, in general for all the echinostomatids, Fried (2001) observed different degrees of compatibility/susceptibility not only towards the second intermediate host, but also towards the first intermediate host snail. In that sense, recently MuñozAntoli et al. (2006) found six snail species susceptible to be infected with $E$. friedi miracidia, with rates of infection up to $36 \%$.

The broad specificity towards second intermediate hosts increases the density of potential host individuals in a particular habitat, helps to maintain a degree of genetic variability in the parasite population, and protects the parasite from the deleterious effects of a local population decline in any single mollusc host species (Evans et al. 1981).

Cercarial infection might be particularly important in the pattern of host utilisation in the natural habitat. Within a community of mollusc hosts, the distribution and occurrence of the metacercarial cysts might reflect the contribution of each host species to the flow of parasites through that community (Evans et al. 1981). The experimental results of second intermediate host utilisation have shown close parallels with that suggested by occasional field studies (McCarthy and Kanev 1990, Morley et al. 2004). Thus, experiments of cercarial infections have been considered appropriate for defining the order of host utilisation as an indirect way to measure the parasite-snail host compatibility. However, variations in parasite-host compatibility could be related to the composition of the snail community, and to protection effects (decoy effects) between snail species with different levels of compatibility (Evans and Gordon 1983).

In the present work, cercarial infectivity of E. albuferensis and E. friedi, under laboratory conditions, in four species of gastropods from the Albufera Natural Park, has been studied as a model to provide some information on the pattern of second intermediate host utilisation in natural systems where different parasite and snail species coexist. Moreover, we combined different snail communities with the purpose of identifying any possible modification in the parasite-snail host compatibility.

\section{MATERIALS AND METHODS}

Cercariae of E. albuferensis and E. friedi were obtained from experimentally infected $G$. chinensis and $R$. peregra snails, respectively. Four species of freshwater snails were exposed to infection with cercariae: $R$. peregra and Lymnaea fuscus (Müller) (Lymnaeidae), Physella acuta (Draparnaud)

Address for correspondence: J.G. Esteban Sanchis, Departamento de Parasitología, Facultad de Farmacia, Universidad de Valencia, Av. Vicente Andrés Estellés s/n, 46100 Burjassot - Valencia, Spain. Phone: ++34 963544 492; Fax: ++34 963 544 769; E-mail: Jguillermo.Esteban@uv.es 
(Physidae) and G. chinensis (Planorbidae). All the snails were laboratory-reared under aquarium conditions and fed with lettuce ad libitum. They were free of larval trematode infections. The size range of all snails employed was $0.3-0.5 \mathrm{~cm}$ (length for lymnaeids and the physid and diameter for the planorbid).

Snails were exposed, using Petri dishes of $8.5 \mathrm{~cm}$ of diameter, to a constant ratio of 20 cercariae/snail in $10 \mathrm{ml}$ of spring water for 24 hours at $20^{\circ} \mathrm{C}$, under constant fluorescent light, and were examined for metacercarial cysts 14 days postexposure. Twenty replicate exposures were conducted for each experiment.

Single-host experiments: 20 specimens of each snail species considered were individually exposed to E. albuferensis or $E$. friedi cercariae.

Two-choice experiments: a couple of two different snail species were exposed simultaneously to E. albuferensis or $E$. friedi cercariae. A total of four two-choice communities were designed mixing lymnaeids with planorbids or physids following the high, low or intermediate degree of compatibility after single-host experiments results. In the case of E. albuferensis the material only reached 3 possible combinations.

Four-choice experiments: four different snail species with different degrees of compatibility were simultaneously exposed to E. albuferensis or E. friedi cercariae.

For all the experiments, cercarial transmission success (CTS) was calculated as the total number of metacercarial cysts established/total number of cercariae exposed $\times 100$ (McCarthy and Kanev 1990). Cyst counts transformed by log $(x+1)$ were used in analysis of variance and the Bonferroni $t$ test, as a post-hoc analysis, was performed to establish the level of parasite-host compatibility. $P<0.001$ was considered as significant.

\section{RESULTS}

The results obtained are shown in Table 1 . In the case of E. albuferensis, single-host experiments analysis of variance revealed significant differences between the numbers of cercariae established in the different snail hosts considered $(\mathrm{P}(F=37.94)<0.01$; D.F. $=4$ and 145). Physella acuta and $R$. peregra had the highest number of metacercariae recovered, without significant differences between them, and approximately 40 times higher CTS values than the other two snail species considered. The lowest number of cysts recovered (lowest CTS values) was found in L. fuscus and G. chinensis, without significant differences between them.

In contrast, in the case of $E$. friedi, analysis of variance revealed no significant differences between the number of cysts recovered in any of the snail hosts considered $(\mathrm{P}(F=1.06)>0.01$; D.F $=4$ and 145$)$. However, nearly 10 times variations of CTS values were detected between snail species: $P$. acuta had the highest CTS, followed by $G$. chinensis and $R$. peregra with intermediate CTS, and finally L. fuscus with the lowest CTS.

In the case of E. albuferensis two-choice experiments, when a physid and a lymnaeid snail species of previous high CTS ( $P$. acuta and $R$. peregra) were exposed simultaneously, both values were significantly lower than in single-host experiments $(\mathrm{P}(t=16.36$ and $4.28)<0.001$; D.F. $=38$ ). When a physid snail of high CTS ( $P$. acuta) was exposed together with a lymnaeid of low CTS (L. fuscus), P. acuta showed a statistically significant reduction of their CTS $(\mathrm{P}(t=4.77)<0.001$; D.F. $=38)$. However, when a lymnaeid and a planorbid snail species of former low CTS ( $L$. fuscus and $G$. chinensis) were exposed simultaneously, the number of cysts recovered in $L$. fuscus was significantly higher than that of single-host experiments $(\mathrm{P}(t=3.00)<0.001$; D.F. $=38)$.

In the case of $E$. friedi, when a physid snail of former high CTS ( $P$. acuta) and a lymnaeid of former intermediate level of CTS (R. peregra) were exposed together, the total number of cysts recovered and the CTS values were significantly reduced compared to those of singlehost experiments $(\mathrm{P}(t=3.19$ and 6.10) $<0.001$; D.F. $=$ 38), respectively. When a physid snail of former high

Table 1. Infectivity of Euparyphium albuferensis and Echinostoma friedi cercariae in single-host, two-choice and four-choice experiments (Abundance - No. metacercariae/examined snail; SE - standard error; CTS - cercarial transmission success).

\begin{tabular}{|c|c|c|c|c|c|c|c|c|}
\hline & \multirow[b]{2}{*}{ Snail species } & \multirow[b]{2}{*}{$\begin{array}{l}\text { No. } \\
\text { cercariae }\end{array}$} & \multicolumn{3}{|c|}{ Euparyphium albuferensis } & \multicolumn{3}{|c|}{ Echinostoma friedi } \\
\hline & & & $\begin{array}{l}\text { \% snails } \\
\text { infected }\end{array}$ & $\begin{array}{l}\text { Abundance } \\
\text { mean } \pm \mathrm{SE}\end{array}$ & CTS & $\begin{array}{l}\text { \% snails } \\
\text { infected }\end{array}$ & $\begin{array}{l}\text { Abundance } \\
\text { mean } \pm \text { SE }\end{array}$ & CTS \\
\hline \multirow[t]{4}{*}{ Single-host } & Physella acuta & 20 & 100 & $11.43 \pm 0.77$ & 57.2 & 85 & $9.72 \pm 6.41$ & 32.5 \\
\hline & Radix peregra & 20 & 100 & $11.57 \pm 0.80$ & 57.9 & 90 & $7.06 \pm 5.46$ & 23.5 \\
\hline & Lymnaea fuscus & 20 & 67 & $2.30 \pm 0.48$ & 11.5 & 85 & $5.76 \pm 5.63$ & 19.3 \\
\hline & Gyraulus chinensis & 20 & 57 & $3.47 \pm 0.70$ & 17.4 & 95 & $7.13 \pm 5.09$ & 23.8 \\
\hline \multirow[t]{8}{*}{ Two-choice } & 1 P. acuta + & 40 & 65 & $5.55 \pm 1.49$ & 13.8 & 55 & $4.30 \pm 1.44$ & 10.7 \\
\hline & 1 R. peregra & & 35 & $0.60 \pm 0.20$ & 1.5 & 45 & $1.25 \pm 0.42$ & 3.1 \\
\hline & 1 P. acuta + & 40 & 70 & $4.70 \pm 1.06$ & 11.7 & 95 & $4.25 \pm 0.81$ & 10.6 \\
\hline & $1 \mathrm{~L}$. fuscus & & 70 & $3.55 \pm 0.67$ & 8.9 & 85 & $3.95 \pm 0.62$ & 9.9 \\
\hline & 1 L. fuscus + & 40 & 90 & $6.75 \pm 1.22$ & 16.9 & 65 & $2.00 \pm 0.45$ & 5.0 \\
\hline & 1 G. chinensis & & 35 & $0.80 \pm 0.35$ & 2.0 & 75 & $2.50 \pm 0.43$ & 6.3 \\
\hline & 1 R. peregra + & 40 & - & - & - & 80 & $2.20 \pm 0.37$ & 5.5 \\
\hline & 1 G. chinensis & & & & & 45 & $1.55 \pm 0.48$ & 3.9 \\
\hline \multirow[t]{4}{*}{ Four-choice } & 1 P. acuta + & 80 & 80 & $12.85 \pm 3.03$ & 16.1 & 65 & $2.35 \pm 0.59$ & 2.9 \\
\hline & 1 R. peregra + & & 35 & $1.60 \pm 0.77$ & 2.0 & 50 & $1.15 \pm 0.39$ & 1.4 \\
\hline & 1 L. fuscus + & & 85 & $7.25 \pm 1.50$ & 9.1 & 70 & $3.55 \pm 0.67$ & 4.4 \\
\hline & 1 G. chinensis & & 60 & $1.50 \pm 0.38$ & 1.9 & 70 & $3.30 \pm 1.06$ & 4.1 \\
\hline
\end{tabular}


CTS (P. acuta) and a lymnaeid snail of former low CTS (L. fuscus) were exposed together, similar cysts were recovered in both snail species, increasing the $L$. fuscus CTS values. When a lymnaeid snail of former low CTS (L. fuscus) and a planorbid snail of intermediate CTS (G. chinensis) were exposed together, an increase in the $L$. fuscus CTS values was observed, but without significant differences unlike in single-host experiments $(\mathrm{P}(t=$ 3.23) $>0.001$; D.F. = 38). However, the number of metacercariae recovered in $G$. chinensis was significantly smaller than in single-host experiments $(\mathrm{P}(t=$ $4.49)<0.001$; D.F. = 38). Finally, when a lymnaeid and a planorbid snail species of former intermediate CTS ( $R$. peregra and $G$. chinensis) were exposed together, a significant reduction of CTS values was noted in both snail species $(\mathrm{P}(t=4.31$ and 6.17$)<0.001$; D.F. $=38)$, respectively.

In the case of E. albuferensis, results of four-choice experiments revealed that the highest CTS values $(P$. acuta and $R$. peregra) in single infections showed a great reduction with statistically significant differences only in $R$. peregra $(\mathrm{P}(t=10.10)<0.001$; D.F. $=38)$. In the four-snail community the lowest CTS values were in $G$. chinensis and R. peregra while the intermediate CTS values were in $L$. fuscus. This situation was similar in the case of $E$. friedi. In the four-snail community, $P$. acuta, the snail with the highest CTS in single-host experiments, showed a significant reduction in the number of recovered metacercariae $(\mathrm{P}(t=4.15)<0.001$; D.F. = 38). Moreover, $R$. peregra and $G$. chinensis, with an intermediate levels of CTS in single infections, showed a significant reduction $(\mathrm{P}(t=3.33$ and 3.81$)$ $<0.001$; D.F. $=38$ ), respectively, to the lowest CTS values in the case of $R$. peregra. In contrast, L. fuscus, the snail with the lowest degree of CTS in single-host experiments, showed an increase to the highest CTS values in the four-snail community.

\section{DISCUSSION}

Euparyphium albuferensis and Echinostoma friedi cercariae are able to infect several aquatic snail species that coexist in the same natural habitat. Despite this broad specificity, not all snail species show the same degree of compatibility with parasites.

It is known that parasite larvae locate their target host responding to chemical conditioning of the environment by intermediate host snails (Smyth and Halton 1983, Haas and Haberl 1997). The orientation behaviour of echinostomatid cercariae has been studied for Echinostoma caproni, E. revolutum, Pseudoechinoparyphium echinatum and Hypoderaeum conoideum. The first three species respond to similar cues of snailconditioned water (Haberl et al. 2000), while H. conoideum cercariae show a different mechanism of chemo-orientation (Haas et al. 1995). The following step after location of the host snail is to penetrate a suitable host individual. In the case of Echinostoma trivolvis, the presence of penetration glands makes pos- sible for cercariae of this species to penetrate some planarians, while E. caproni, which lacks such glands, is unable to penetrate these planarians (Fried et al. 1995). In the case of E. albuferensis and E. friedi, species which both are able to penetrate the same snail species, we could assume that similar mechanisms are used to locate and penetrate the second intermediate hosts. However, different levels of compatibility appear between the snail species considered, with differences observed in the cercarial transmission success (CTS).

In the case of Echinoparyphium recurvatum cercariae infecting Radix peregra, the mean number of cysts recovered per snail is positively correlated to the number of same-species snails per cage (McCarthy 1990). This could be explained by the fact that higher number of snails could produce greater conditioning intensity, and therefore would be expected to attract greater numbers of cercariae. However, in snail communities formed by different snail species, the overall transmission success could not be increased, probably due to the antagonistic effect of one chemical over another. In this sense, our results with E. albuferensis and E. friedi show that CTS does not increase with the number of different snail species per cage. Moreover, the effect of the cercarial dilution upon the choice of different snail species of the community could expect a reduction of the transmission levels (Christensen 1980, Combes and Mone 1987). In this sense, mention should be made of the results obtained with $E$. friedi, when a snail of high CTS (Physella acuta) was exposed to cercariae together with a snail of intermediate CTS $(R$. peregra): the total number of metacercariae recovered was smaller than in single infections in both snail species. In four-choice combinations, $P$. acuta, the snail with the highest CTS in single infections, presented a sharp decrease in the number of recovered metacercariae, exhibiting a low degree of compatibility with the parasite.

Evans et al. (1981) proposed several factors likely to be important in determining the probability that cercariae encounter a mollusc host species, and thus capable of influencing CTS: temporal and spatial overlap between host and parasite, mollusc habitat preferences, existence of cercarial chemotaxis to one or more host species, and relative target size of each host species. McCarthy (1990) proposed the second intermediate host dispersion pattern as another host-related factor capable of influencing the levels of cercarial transmission. In any case, variable susceptibility to infection among snails has been demonstrated: laboratory infections of E. recurvatum cercariae (Evans et al. 1981) have indicated that $R$. peregra is highly susceptible, while planorbid snail species are only moderately susceptible, and some prosobranch gastropods are non-susceptible; high degree of compatibility of Pseudoechinoparyphium echinatum has been shown for planorbids and lymnaeids, while prosobranchs are rarely infected (McCarthy and Kanev 1990); Echinostoma caproni cercariae (refereed to as E. liei by Christensen et al. 
1980) found five species of the genus Bulinus and $P$. acuta to be very susceptible, whereas Lymnaea natalensis, Helisoma duryi and three species of Biomphalaria, which act as first intermediate hosts, showed a lower degree of susceptibility (Christensen et al. 1980); E. trivolvis encysts more readily in Biomphalaria glabrata than in Helisoma trivolvis, Physa heterostropha or Corbicula fluminea (Anderson and Fried 1987, Fried et al. 1987, Huffman and Fried 1990). However, the mechanisms underlying the differences in compatibility among snail species remain unknown.

We have carried out different snail host communities infections to evaluate the level of parasite-snail compatibility. In E. albuferensis single-host infections, $R$. peregra and $P$. acuta snails showed the highest degree of compatibility, while in the case of $E$. friedi only $P$. acuta showed high levels of compatibility with the parasite and $R$. peregra seemed to reduce its compatibility to an intermediate level. In contrast, Gyraulus chinensis and Lymnaea fuscus showed a low degree of compatibility with E. albuferensis cercariae under single-host infections, while in the case of E. friedi, $G$. chinensis showed an intermediate level of compatibility. Under multiple-choice conditions, lymnaeid snail species are subjected to a great compatibility modification, while $L$. fuscus increased to the highest or to an intermediate level of compatibility in E. friedi and E. albuferensis infections, respectively, $R$. peregra snails reduced their level to low compatibility in both parasite species.

Evans et al. (1981) reported that individual snails acting as first intermediate host are predisposed to infection by the cercariae which emitted by themselves. In this context, Evans and Gordon (1983) showed that $E$. recurvatum cercariae had a high degree of preference for $R$. peregra, its first intermediate host. However, our results do not agree with those observations. In the case of E. albuferensis it was shown that $G$. chinensis both, in single- and multiple-choice combinations, yielded the lowest number of metacercariae recovered. In the case of $E$. friedi, although $R$. peregra in single infections seems to show an intermediate level of compatibility, when that snail specie is in multiple-choice combination as happens in nature, the amount of metacercariae recovered decreases. In any case, low compatibility of cercariae with the snail first intermediate host may constitute a mechanism preventing metacercarial superinfection and preventing parasite pressure on the first intermediate host population (McCarthy and Kanev 1990).

Differential compatibility is independent of the phyletic position of the host. McCarthy and Kanev (1990) showed different degrees of compatibility among the lymnaeid species $R$. peregra, $L$. fuscus and L. stagnalis, and among the planorbid snail species Planorbarius corneus and Planorbis planorbis. In our single-infections experiments, E. albuferensis showed high CTS values in $R$. peregra, while $L$. fuscus showed the lowest. In the case of $E$. friedi, cercariae showed an intermediate preference for $R$. peregra and a lowest preference for $L$. fuscus.

Our results verified that, in constant water level experiments, high densities of hosts exhibiting only low suitability may in fact reduce the level of parasite transmission, but the presence of gastropods of high compatibility contributes to increase the susceptibility of those with low compatibility. In this sense, we have shown in the two-choice combinations of E. albuferensis and E. friedi that the snail of low compatibility ( $L$. fuscus) is able to increase its CTS. Furthermore, in $E$. albuferensis four-choice combinations, the snails with the previous highest CTS ( $P$. acuta and $R$. peregra) showed a significant reduction, mainly in the case of $R$. peregra. Again, these results are similar to those obtained in E. friedi four-choice combinations, where $L$. fuscus reached the highest CTS values. The possible explanation of $L$. fuscus increase in compatibility levels in host communities could be that as the cercariae are stimulated by the other snail species stimulus, the easy penetrability in this snail species allows for the high rates of metacercarial cysts recovered.

All the results obtained demonstrated that the degree of parasite-host compatibility of each snail species considered could be determined by the presence of others. The total transmission pattern of two sympatric parasite species sharing the same second intermediate host spectrum in a particular habitat, as is the case of E. albuferensis and E. friedi in the Albufera Natural Park, seems to depend on the interactions between snail species communities.

Acknowledgements. The present study was supported by the Proyect CGL2005-02321/BOS from Ministerio de Educación y Ciencia (Spain) and FEDER (European Union) and by the Proyect GV07/006 and Ayuda Complementaria ACOMP 07/071 from the Conselleria d'Empresa, Universitat i Ciència de la Generalitat Valenciana (Valencia, Spain). The authors wish to thank M. Trelis for her collaboration.

\section{REFERENCES}

ANDERSON J.W., FRIED B. 1987: Experimental infection of Physa heterostropha, Helisoma trivolvis and Biomphalaria glabrata (Gastropoda) with Echinostoma revolutum (Trematoda) cercariae. J. Parasitol. 73: 49-54.

CHRISTENSEN N.Ø. 1980: A review of the influence of hostrelated and parasite-related factors and environmental conditions on the host-finding capacity of the trematode miracidium. Acta Trop. 37: 303-318.
Christensen N.Ø., Frandsen F., Roushdy M.Z. 1980: The influence of environmental conditions and parasite-intermediate host-related factors on the transmission of Echinostoma liei. Z. Parasitenkd. 63: 47-63.

Combes C., Mone H. 1987: Possible mechanisms of the decoy effect in Schistosoma mansoni transmission. Int. J. Parasitol. 17: 971-975.

Esteban J.G., TOledo R., SÁNChez L., MuÑOz-ANTOli C. 1997: Life-cycle of Euparyphium albuferensis n. sp. (Trema- 
toda: Echinostomatidae) from rats in Spain. Syst. Parasitol. 38: 211-219.

EVANS N.A., GORDON D.M. 1983: Experimental observations on the specificity of Echinoparyphium recurvatum toward second intermediate hosts. Z. Parasitenkd. 69: 217-222.

EVANS N.A., WHITFIELD P.J., DOBSON A.P. 1981: Parasite utilization of host community: the distribution and occurrence of metacercarial cysts of Echinoparyphium recurvatum (Digenea: Echinostomatidae) in seven species of molluscs at Harting Pond, Sussex. Parasitology 83: 1-12.

FRIED B. 2001: Biology of echinostomes except Echinostoma. Adv. Parasitol. 49: 163-210.

FRIED B., EMILI S., ETTINGER W.S. 1987: Experimental infection of Corbicula fluminea (Bivalvia: Corbiculidae) with Echinostoma revolutum cercariae. J. Parasitol. 73: 655-656.

FRIED B., IDRIS N., OSHAWA T. 1995: Experimental infection of juvenile Biomphalaria glabrata with cercariae of Echinostoma trivolvis. J. Parasitol. 81: 308-310.

HAAS W., HABERL B. 1997: Host recognition by trematode miracidia and cercaria. In: B. Fried and T.K. Graczyk (Eds.), Advances in Trematode Biology. CRC Press, Boca Raton, Florida, pp. 197-227.

HAAS W., HABERL B., KALBE M., KÖRNER M. 1995: Snail-hostfinding by miracidia and cercariae: chemical host cues. Parasitol. Today 11: 468-472.

Haberl B., Körner M., SPengler Y., Hertel J., Kalbe M. HAAS W. 2000: Host-finding in Echinostoma caproni: mirac-

Received 7 November 2007 idia and cercariae use different signals to identify the same snail species. Parasitology 120: 479-486.

HUFFMAN J.E., FRIED B. 1990: Echinostoma and echinostomiasis. Adv. Parasitol. 29: 215-269.

MCCARTHY A.M. 1990: The influence of second intermediate host dispersion pattern upon the transmission of cercariae of Echinoparyphium recurvatum (Digenea: Echinostomatidae). Parasitology 101: 43-47.

MCCARTHY A.M., KANEV I. 1990: Pseudoechinoparyphium echinatum (Digenea: Echinostomatidae): experimental observations on cercarial specificity towards second intermediate hosts. Parasitology 100: 423-428.

MORLEY N.J., LEWIS J.W., ADAM M.E. 2004: Metacercarial utilization of a naturally infected single species (Lymnaea peregra) snail community by Echinoparyphium recurvatum. J. Helminthol. 78: 51-56.

MuÑoz-ANTOli C., TRelis M., Toledo R., Esteban J.G. 2006: Infectivity of Echinostoma friedi miracidia to different snail species under experimental conditions. J. Helminthol. 80: 323-325.

SMYTH J.D., HALton D.W. 1983: The Physiology of Trematodes. 2nd Edition. Cambridge University Press, Cambridge, 446 pp.

Toledo R., MuÑOZ-AnTOli C., Esteban J.G. 2000: The lifecycle of Echinostoma friedi n. sp. (Trematoda: Echinostomatidae) in Spain, and a discussion on the relationships within the "revolutum" group based on cercarial chaetotaxy. Syst. Parasitol. 45: 199-217.

Accepted 21 February 2008 